\section{Day care surgery for infants and children}

The concept of outpatient, same-day, or day care surgery (DCS) in children is not new.' Indeed, children are ideally suited for this approach and an expansion of paediatric DCS has occurred during the past decade. Many articles, book chapters and reviews have been published on the topic of paediatric DCS. ${ }^{2-7}$

Cloud $^{4}$ and Shah ${ }^{8}$ suggested independently that at least 50 per cent of surgery in children could be done on an outpatient basis. Our institution (C.H.E.O.) provides all paediatric surgical services for all children under 14 years of age in the city of Ottawa, and the utilization rate for elective DCS is currently approaching 50 per cent of all elective procedures requiring anaesthesia. Excluding emergency surgery, DCS was employed for an average 34.7 of all cases during 1980,1981 and 1982. This proportion rose rapidly to 43.6 per cent during the first three months of 1983, following a hospital cost-containment programme that involved closure of some inpatient beds, but did not produce any change in total surgical procedures performed.

\section{Advantages}

Apart from the benefits of DCS in adults summarized elsewhere in this issue, additional advantages have been identified in children. ${ }^{5,9}$ There is a general, as well as financial benefis to the family unit in that there is reduced dislocation to family life relating to parent's time off work, travel to and from hospital, arranging baby-sitters, etc. The child's separation from his parents and home are minimized so that the behavioural disturbances associated with separation and hospitalization are reduced. The parents are actively and continuously involved with the care of their child in DCS units as opposed to their peripheral role when children are admitted as inpatients. There is a decreased risk of hospital-acquired infections because of the reduced contact with potentially infectious hospital staff and
Gary G. Johnson MD

inpatients. Finally, there is a financial saving for both the institution and parent.

\section{Guidelines}

Clear written guidelines should outline general criteria for admission to and discharge from DCS units for children. As well, the guidelines should address other factors relating to patient selection and preparation.

\section{A Surgical selection}

Admission criteria must be agreed upon by surgeons and anaesthetists regarding the types of surgical procedures and other considerations relating to the planned surgery (Table 1). There should be some flexibility in applying the guidelines. For instance, we deviate from the guidelines by allowing dental surgery patients to be discharged the same day after surgery lasting up to three hours. Controversy exists concerning adeno-tonsillar surgery done on an outpatient basis. Currently 12 per

TABLE I Criteria for pediatric day care surgery

Surgery Duration less than two hours Minimal bleeding

No infected or infectious cases

No major body cavity entered

No complications expected

No major or persistent nausea and vomiting

No major pain

No special nursing care post-op

No IV or IM drugs needed post-op

Ready for discharge by 6:00 PM

Dr. G.G. Johnson, Chairman \& Programme Director, Dept. of Anaesthesiology, University of Ottawa, Children's Hospital of Eastern Ontario, 401 Smyth Road, Ottawa, Ontario, KIH 8L1. 
TABLE II Special problems of prematures and ex-prematures

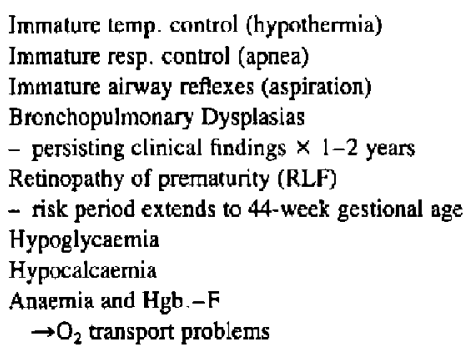

cent of such patients in our hospital are managed as outpatients. This approach appears reasonable so long as blood loss has been less than five per cent of estimated blood volume, the family lives within commuting distance of the hospital, discharge criteria have been met, and post-op instructions are understood.

\section{B Patient selection}

In addition to the surgical and other matters itemized in Table I there are patient, parent and home factors that must be considered in accepting patients for paediatric DCS.

(i) Patient: Any child in good general health (ASA physical status I or II) is accepted by most DCS units. Steward has suggested that DCS may actually be ideal for ASA class III patients whose systemic disease is well controlled. Infants require special consideration. Any full-term healthy infant is accepted into our DCS unit whereas some units exclude infants up to six months of age. Special caution must be exercised in dealing with exprematures, * who may have many potential residual problems (Table II). Our unit excludes ex-prematures and ex-low birth weight $\dagger$ infants for admission through DCS until they are six months of age. The major reason for requiring ovemight admission in these children is the high incidence ( 25 per cent) of ex-premature infants exhibiting apnoea in the 12 hours post-anaesthesia. ${ }^{9}$ Ex-prematures are also at risk for retinopathy of premarurity (RLF) up to 44 weeks of gestational age. Ex-RDS patients may have bronchopulmonary dysplasia (BPD) and

*Premature - less thar 37 weeks gestational age at birth.

†Less than 2500 grams at birth. at least ten per cent have persisting clinical and radiologic findings present for one to three years. In addition, ex-prematures are also vulnerable to hypothermia, hypoglycaemia, aspiration, and anaemia.

(ii) Parent and home situation: The parents must agree with and be capable of understanding their role in providing minimal nursing care for their child following DCS. They should live within a reasonable commuting distance ( 1 hour or 30$40 \mathrm{~km}$ ). One parent or guardian must accompany the child to the hospital and they should travel by taxi or with someone else driving, so that the parent/guardian can attend the child closely during the return trip home. Typed, complete discharge instructions should be given to the parent regarding continuing care along with contact name(s) and number(s) in case of problems.

\section{c Assessment}

The basic assessment of children prior to DCS is the same as for in-patients. A medical questionnaire, such as that developed at the Hospital for Sick Children in Toronto ${ }^{6}$ is most useful, both in obtaining and standardizing pertinent information and in providing an economy of effort and time at the pre-anaesthetic visit.

Haemoglobin measurement and urinalysis are mandatory. Additional investigation (chest $x$-ray, $E K G$, etc.) should only be ordered for specific indications. Sickledex is recommended for black patients.

In comparison with in-patient surgery, cancellation rates are generally higher in paediatric DCS units for many different reasons. Over the past three years at C.H.E.O., 4.5 per cent of DCS patients were cancelled after arrival in the unit whereas 3.2 per cent were cancelled while at home, in the 48 hours prior to admission to DCS. Cancellations at home were mainly because of acute URI's, fever $\left(>38^{\circ} \mathrm{C}\right)$, infectious diseases and diarthoea. Operations were cancelled, after patient assessment in the DCS unit, for the above problems, plus skin lesions, anaemia, lesion size changes, abnormal urinalysis or disregarded NPO status. Other problems unrelated to the patient included missing documentation and parent or surgeon factors.

The overall cancellation rate for DCS patients is 7.7 per cent at C.H.E.O., substantially less than the 18.0 per cent reported from a paediatric urology series by Kroovand. ${ }^{10}$ 


\section{Preparation}

Efforts must be made to minimize the known post-hospitalization behaviour problems associated with hospitalization of children and separation from parents. Accordingly, preparation of the child begins with the parent being provided with clear written instructions advising on all aspects of DCS, so that the parent can re-inforce the instructions and answer their children's questions. In addition, preoperative classes and tours have been found to be most beneficial to both the child and the parent. Captioned photo albums in our DCS reception area have also been particularly useful to both staff and parents to explain and prepare the child immediately prior to anaesthesia and surgery. An activity area for the young child adjacent to the DCS unit keeps the child occupied, content and together with his parent up to the time of induction.

Overnight fasting in children may be associated with asymptomatic hypoglycaemia -30 per cent in one study. ${ }^{11}$ Children should be given clear fluids containing sugar up to four hours pre-anaesthetic. Some controversy exists over the NPO status in the breast-fed child. In our unit, they are breast-fed five hours prior to planned anaesthesia and allowed clear dextrose and water up to three hours preoperatively.

\section{Anaesthetic considerations}

Above all, the staffing levels, equipment, monitoring and facilities must be the equivalent of that found in main OR's and recovery rooms elsewhere in the institution. It is not a "step-down" unit for minor surgery on minors.

A Premedication has been progressively abandoned in paediatric DCS units, especially where it involves an IM injection which is viewed as a painful assault. Different views exist concerning the actual value of using standardized premedication on all patients. ${ }^{7,9,12}$ Anticholinergics may be given orally, either alone, or with sedative drugs such as pentobarbital or Diazepam (Table III). We recommend the use of atropine IV $\left(0.02 \mathrm{mg} \cdot \mathrm{kg}^{-1}\right.$ to maximum $0.4 \mathrm{mg}$ ) at the time of induction in children less than ten years of age.

B Anaesthetic techniques should be oriented to producing rapid recovery to "street fitness" with the least post-anaesthetic implications. General anaesthesia is the commonest technique used for
TABLE III Premedication

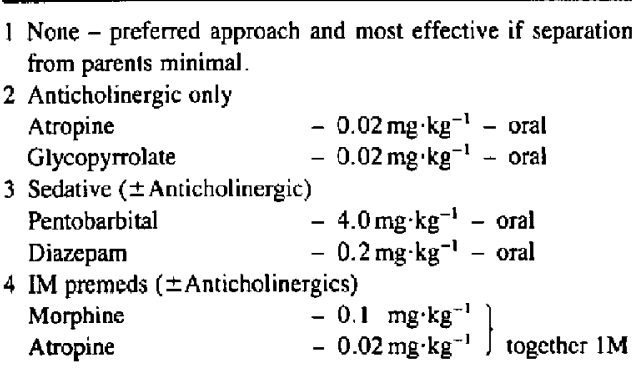

pacdiatric DCS. Co-operation of children with regional anaesthesia is poor. However, regional anaesthesia - supplemented general anaesthetics (c.g., caudal for circumcisions) are associated with earlier, smoother arousal and decreased inhalation concentrations. ${ }^{13}$

c Induction techniques (Table IV) vary with the age of the child and his/her individual response or ca-operation. Because of the small, easily obstructed airway and instability with potent inhalation anaesthesia, the newborn ( $<1$ month) may be dealt with most safely by awake intubation or by careful inhalation induction.

Children under one year of age are easily induced with inhalational agents using clear masks (treated with flavouring extracts in some units). In whichever age group inhalation techniques are used, they have the advantage of more rapid early recovery than that seen with barbiturate inductions, although later "street-fitness" is generally equivalent. The usc of intramuscular succinylcholine $\left(2 \mathrm{mg} \cdot \mathrm{kg}^{-1}\right)$ after inhalation induction in young children shortens the time to intubation and reduces the exposure to high concentrations of potent inhalation agents.

TABLE IV Induction techniques

\begin{tabular}{|c|c|c|}
\hline Age & $\begin{array}{l}\text { Problem or } \\
\text { concern }\end{array}$ & Techniques \\
\hline$<1 \mathrm{mo}$ & Small, unstable & Awake \\
\hline$<1 \mathrm{yr}$ & Small size & Inhalation \\
\hline Toddler (1-4) & Separation & Inhal'n, rectal, IV \\
\hline $\begin{array}{l}\text { School age } \\
(5-12)\end{array}$ & Mutilation & Inhal'n, rectal, IV \\
\hline Teens $(>12)$ & $\begin{array}{l}\text { Loss of Control } \\
\text { Death } \\
\text { (Mutilation) }\end{array}$ & IV \\
\hline
\end{tabular}


TABLE V Discharge eriteria for pediatric D.C.S.

1 Patient's condition assessed by anaesthetist

2 Appropriate consciousness-alertness for age

3 Appropriate stable vital signs for age

4 Appropriate ambulation for age

5 No respiratory signs or symptoms

6 Absence of nausea and vomiting

7 Tolerates small ampunts of oral fluids

8 No major pain - controlled by oral meds.

9 No bleeding

10 No fever

11 Written clear discharge instructions with contact names and phone numbers

Pre-school children's major concern is with separation from parents. This one to four year age group is difficult to reason with. Induction choices are wider, employing rectal, inhalational or IV induction and depend on the patient. Rectal induction is becoming more popular using methohexital (20-40 mg $\mathrm{kg}^{-1}$ ) and patient acceptance is excellent, leading to light sleep in eight to ten minutes. There is however a longer recovery room time compared with halothane along. ${ }^{9}$ Smooth inhalation or IV induction with small gauge needles (\#25 or \#27) may be well accepted by a composed pre-school child.

School age children (5-12) may be reasoned with, and intravenous induction is the preferred approach in our DCS employing thiopental $\left(5 \mathrm{mg} \cdot \mathrm{kg}^{-1}\right)$ rather than methohexital $\left(1.5 \mathrm{mg} \cdot \mathrm{kg}^{-1}\right)$ since the latter produces pain on injection and is associated with apnoea, hiccoughs, and involuntary muscle movements.

Teen-agers have many fears (loss of control, death, body disfigurement) when they present for surgery. A rapid smooth IV induction is the best choice. Muscle pain and cramps following the use of succinylcholine may be reduced by the use of defasciculating doses of curare $\left(0.05 \mathrm{mg} \cdot \mathrm{kg}^{-1} \mathrm{IV}\right)$ in children over the age of four years.

Parents' presence at induction may be very useful, although some controversy exists. ${ }^{14}$ The parent may actually assist, for instance, with placement of the rectal catheter in the pre-school children. Proponents suggest this leads to greater patient cooperation and smoother induction. Because of logisties and physical plant, we limit parents' presence during induction, to those children with communication problems (deaf, autistic, retarded, etc.).
Induction in the difficult to manage (or unmanageable) patient may be facilitated by the use of intramuscular drugs as ketamine $\left(3-5 \mathrm{mg} \cdot \mathrm{kg}^{-1}\right.$ ) or methohexital $\left(8-10 \mathrm{mg} \cdot \mathrm{kg}^{-1}\right)$ and by rectal agents, ${ }^{15}$ preferably methohexital $\left(20-40 \mathrm{mg} \cdot \mathrm{kg}^{-1}\right)$. The parents' presence and participation is a decided advantage in such circumstances and is recommended.

\section{Maintenance of anaesthesia}

General inhalational anaesthesia is preferred for DCS, with halothane and isoflurane being most suitable. Non-rebreathing circuits are preferred.

Intravenous narcotics are being administered 15-20 minutes prior to the end of anaesthesia in unpremedicated patients, providing a smoother pain-free emergence (fentanyl $0.05-0.1 \mu \mathrm{g} \cdot \mathrm{kg}^{-1}$ ) or (morphine $0.05-0.1 \mathrm{mg} \cdot \mathrm{kg}^{-1}$ ). Another highly recommended approach which is increasing in use, is regional anaesthesia employed as a supplement to general anaesthesia. ${ }^{33}$ Decreased concentrations of inhalational anaesthetics are required and the patients have a faster, smoother emergence. Specific blocks (e.g., caudal epidurals) or field infiltration may be used depending on the surgical site.

Intubation should be used appropriately in paediatric DCS and there should be no inhibition to use endotracheal tubes because of excessive concern of post-intubation croup. Our experience is similar to others, who rarely experience this complication..$^{5} 16$ However, $S$ mith ${ }^{17}$ reported a five per cent incidence of post-intubation croup, most of whom responded well - only one quarter of these croup patients required admission overnight. With careful laryngoscopy and an air leak around the tracheal tube during the application of airway positive pressure of $20 \mathrm{~cm} \mathrm{H} \mathrm{H}_{2} \mathrm{O}$, traumatic croup is avoidable. If croup does occur, it should appear within one to two hours at the latest, and usually within 30 minutes. Obviously, where a two-hour recovery period in DCS is required for patients who have been intubated, croup would be identified well before discharge.

\section{E Recovery-discharge}

Standard recoyery care is given and the recovery time tends to correspond to the anaesthesia time but may be delayed by the use of IV barbiturates or narcotics and rectal barbiturates. Recovery scoring 
systems are used widely and serve mainly to focus nursing attention on the physiologic items being scored.

Discharge criteria should be clear, but need to be modified to take into account the maturing infant and child, with the attendant changes in vital signs and motor-cognitive development (Table V). The anaesthetist should discharge the patient, after a minimum period of one hour of recovery.

\section{F Complications}

Minor complications occur as frequently in paediatric DCS as with adults and various complication rates have been reported in children, however admission is seldom required because of them. ${ }^{9}$

Approaches to minimizing complications are presented elsewhere by Dr. Edelist. In our hospital, only 15 out of $5686 \mathrm{DCS}$ patients ( 0.26 per cent) have required admission in a three-year survey mainly for bleeding, or prolonged nausea and vomiting, and once each for seizure and croup.

With clear guidelines for selection of patients, types of surgery, and discharge criteria, anaesthesia for children in a DCS is safe and the few complications that do occur, are the same minor complications associated with all short paediatric anaesthetics. Utilization of paediatric DCS will continue to increase and will be the commonest approach for short elective surgery in children because of the obvious financial and psycho-social benefits, for the family units.

\section{References}

1 Nicoll JH. The surgery of infancy. Br Med J 1909; 2: 753 .

2 Kay B. Out-patient aracsthesia, especially for children. Acta Anaesthesiol Scand (Suppl) 1965; 17: 421.

3 Davenport $H T$, Shat $C P$, Robinson $G C$. Day surgery of children. Can Med Assoc J 1971; 105 : 498-501.

4 Cloud, DT, Reed WA, Ford JL, et al. The surgicenter: A fresh concept in outpatient paediatric surgery. J Pediatr Surg 1972; 7: 206-12.

5 Steward $D J$. Out-patient paediatric anaesthesia. Anaesthesiology 1975; 43: 268-76.

6 Steward DJ. Anaesthesia for pediatric out-patients. Can Anaesth Soc J 1980; 27; 412-16.
7 Smith $R M$ Anaesthesia for infants and children. 4th Ed. St. Louis, Toronto: Mosby, 1980 (Chapter 22).

8 Shah CP. Day care surgery in Canada: Evolution, policy and experience of provinces. Can Anaesth Soc J 1980; 27: 399-405.

9 Miller RD Anesthesia. New York: Churchill Livingstone, 1981 (Chapter 40).

10 Kroovand $R L$, Perlmulter $A D$. Short stay surgery in pediatric urology. J Urol 1978; 120: 483.

11 Bevan JC, Burn MC. Acid-base and blood glucose levels of pediatric cases at induction of anaesthesia: the effects of pre-operative starvation and feeding. Br J Anaesth 1973; 45: 115.

12 Desjardins $R$, Ansara S, Charest J. Pre-anaesthetic medication in paediatric day care surgery. Can Anaesth Soc J, 1981; 28: 141-8.

13 Shandling $B$, Steward $D J$. Regional analgesia for post-operative pain in paediatric outpatient surgery. J Ped Surg 1980; 15: 477-80.

14 Hannallah RS, Rosales $J K$. Experience with parents' presence during anaesthesia induction in children. Can Anacsth Soc J 1983; 30: 286-9.

15 Goresky GV, Steward DJ. Rectal methohexitone for induction of anaesthesia in children. Can Anaesth. Soc J. 1979; 26: 213-15.

16 Braun $J P$. Outpatient nasotracheal anesthesia for children's dentistry. NZ Dent J 1977; 73 : 77.

17 Smith FK, Deputy BS, Berry FA. Outpatient anesthesia for children undergoing extensive dental treatment. J Dis Child 1978; 45; 142. 